\title{
Cathepsin B in osteoarthritis: cytochemical and histochemical analysis of human femoral head cartilage
}

\author{
Antonio Baici, Angela Lang, Dorothy Hörler, Rudolf Kissling, Claude Merlin
}

\begin{abstract}
Objective-To localise the cysteine endopeptidase cathepsin $B$ in chondrocytes and cartilage from normal and osteoarthritic (OA) human femoral heads in order to provide qualitative information on its cellular expression and distribution at possible sites of action.
\end{abstract}

Methods-OA articular cartilage was obtained at surgery for total hip replacement; control cartilage was obtained at postmortem. Chondrocytes were isolated by sequential enzymatic digestion and cathepsin $B$ analysed by immunocytochemistry and activity staining with a fluorogenic substrate. Lysosomes were visualised by fluorescence microscopy after staining of living cells with acridine orange. Using a histochemical reaction, enzyme activity was measured in cryosections of full thickness cartilage.

Results-Chondrocytes from normal cartilage contained very few lysosomes and only a minor cell population was cathepsin $B$ positive. A high proportion of chondrocytes from active $O A$ cartilage contained a large number of lysosomes and an excess of cathepsin $B$ in intracellular organelles; the enzyme was stored in an active form. In this respect, $O A$ chondrocytes closely resembled normal cells that had been phenotypically modulated by serial subcultures. No cathepsin B activity could be detected by histochemistry in either chondrocytes or matrix of normal cartilage. While apparently intact and severely degraded OA cartilage was also cathepsin $B$ negative, tissue at sites of active destruction and, particularly, at repair sites was highly positive.

Conclusion-The presence and the particular distribution of active cathepsin $B$ in OA cartilage at 'more involved' sites suggest a pathological role for this enzyme in sustaining and perpetuating cartilage degradation. While other stimuli may also be responsible for cathepsin $B$ expression in OA chondrocytes, the similarity with artificially modulated cells indicates fibroblastic metaplasia as a plausible mechanism.

(Ann Rheum Dis 1995; 54: 289-297)

Cathepsin B has been proposed as a mediator of cartilage autodegradation without the intervention of exogenous stimuli. ${ }^{1-3}$ Significantly greater concentrations of this enzyme have been documented in human OA cartilage compared with normal tissue. ${ }^{4-6}$ A role for cathepsin B in interleukin-1 (IL-1) stimulated cartilage proteoglycan degradation has been suggested using explants of bovine nasal ${ }^{7-9}$ and articular cartilage. ${ }^{9}$ The involvement of cathepsin B proposed in this context was not enhanced enzyme biosynthesis and secretion followed by direct action on aggrecan, but rather intracellular activation of the latent form of a cytokine stimulated metalloproteinase acting as the effective mediator of degradation. ${ }^{9}$ These results are in keeping with our observation that cathepsin B biosynthesis and intracellular storage is only moderately stimulated upon chondrocyte activation through IL- $1 \beta$, while its secretion is not. ${ }^{10}$

A dramatic means of stimulating chondrocytes to produce cathepsin B is by phenotypic modulation. While normal chondrocytes synthesise and store the enzyme intracellularly in very low amounts without secreting it, they greatly enhance biosynthesis, storage, and secretion of cathepsin B after phenotypic modulation in monolayer culture. ${ }^{11}$ This property is reversible and cathepsin B reverts to normal levels after reconstitution of the original chondrocyte phenotype. ${ }^{11} 12$

In the accompanying study, ${ }^{6}$ cathepsin B activity was quantitatively determined in zones of articular cartilage from different anatomical regions and this information was assessed in relation to the severity of tissue degradation. The present investigation complemented that study and aimed to show, from a qualitative point of view, the cellular origin and sites of action of cathepsin B, by screening cells and extracellular matrix of human normal and OA cartilage.

\section{Materials and methods}

CELL ISOLATION

OA femoral heads were obtained at total hip replacement, and control specimens at postmortem. Details of sampling, documentation, definition of the anatomical position of cartilage and of its type ${ }^{13}$ were as in the accompanying paper; ${ }^{6}$ all subsequent operations were carried out under a laminar flow. The table includes a summary of the diagnoses for the OA femoral heads considered in this study. OA samples were designated by a three digit number and control specimens of cartilage identified by the prefix 'control' 
using the previous numbering system, ${ }^{6}$ as some samples were common to both this and the previous study. The femoral heads were thoroughly rinsed with Hank's balanced salt solution (HBSS) and slices of cartilage were removed with a scalpel, transferred to Petri dishes, and maintained overnight in organ culture in Ham's F-12 medium (Gibco, Grand Island, NY, USA) containing $10 \%$ heat inactivated fetal calf serum (FCS), $0.1 \mathrm{mg} / \mathrm{ml}$ ascorbic acid (added in this high concentration only at this stage and omitted later ${ }^{14}$ ), $100 \mathrm{IU} /$ $\mathrm{ml}$ penicillin and $100 \mu \mathrm{g} / \mathrm{ml}$ streptomycin. Cartilage from OA femoral heads was sampled from osteophyte free areas of the anterior and posterior regions; control cartilage also included the superior region. The cartilage slices were then washed twice in HBSS, finely diced and the whole tissue obtained from a femoral head incubated for one hour at $37^{\circ} \mathrm{C}$ under gentle stirring in a mixture of $30 \mathrm{ml}$ of Ham's F-12 medium containing $54 \mathrm{U} / \mathrm{ml}$ pronase E from Streptomyces griseus (Fluka, Buchs, Switzerland) and $10 \mathrm{ml}$ of $1 \mathrm{x}$ trypsinEDTA solution $(0.5 \mathrm{~g} / 1$ trypsin 1:250, $0.2 \mathrm{~g} / 1$ EDTA in modified Puck's saline A, Gibco). The supernatant was discarded, the pellet washed twice in HBSS and digested for one to two hours with $0 \cdot 2 \%$ collagenase from Clostridium histolyticum, type III, $144 \mathrm{U} / \mathrm{mg}$ (Worthington, Freehold, NJ, USA) in F-12 medium containing penicillin and streptomycin (concentrations as above) and $10 \%$ FCS. After settling of debris, the supernatants were centrifuged at $300 \mathrm{~g}$ and the digestion was repeated in the same way on the pellets for a further two to three hours with fresh reagents. The supernatants of the two digestions were pooled and the cells were washed twice with F-12 medium before being further processed. Cells were incubated in a humidified chamber at $37^{\circ} \mathrm{C}$ and an atmosphere consisting of $5 \%$ carbon dioxide in air. We demonstrated that modulation of the chondrocyte phenotype by serial monolayer subcultures in a nutrient rich medium (Dulbecco's modified Eagle's medium (DMEM), Gibco) resulted in a considerable increase of synthesis, storage, and secretion of cathepsin B. Within the first week in primary culture, however, cathepsin B expression was barely detectable. ${ }^{11}$ In the present study we did not observe stimulation of cathepsin B in primary culture for at least two weeks when the cells were cultured in a nutrient poor medium such as Ham's F-12. Therefore, for the purpose of inducing dedifferentiation, chondrocytes from normal cartilage were plated at $2 \times 10^{6}$ cells in $25 \mathrm{~cm}^{2}$ culture flasks in DMEM supplemented with $10 \% \mathrm{FCS}$ and $2 \mathrm{mmol} / \mathrm{l}$ glutamine. These cells were subcultured after trypsinisation of confluent monolayers. ${ }^{11}$ Otherwise, to evaluate chondrocytes in a condition as near as possible to that in the original tissue, the cells were plated in F-12 medium as detailed below.

IMMUNOCYTOCHEMISTRY

For enzyme immunolocalisation, $1 \times 10^{4}$ chondrocytes in $0.1 \mathrm{ml}$ of the appropriate medium containing $10 \%$ FCS were plated on round glass cover slips (15 $\mathrm{mm}$ diameter) previously sterilised with ultraviolet light. With plastic cover slips results were similar, but preparations were qualitatively inferior for microphotography. For the demonstration of the cathepsin B content in freshly isolated chondrocytes, the cells were not cultured, but simply allowed to adhere to cover slips in F-12 medium (40 hours to six days), while only the artificially modulated cells from subcultures were incubated in DMEM (see the preceding section). Adherent cells were washed with serum free medium and stained for cathepsin $B$ with the avidin-biotin-peroxidase method ${ }^{15}$ using the IgG fraction of affinity purified sheep anti-rabbit cathepsin $B$ antibodies. ${ }^{16}$ These cross reacted with human spleen cathepsin B purified as described. ${ }^{17}$ Controls were incubated with chromatographically purified nonimmunised sheep IgG. ${ }^{15}$ Addition of FCS to F-12 medium over a short period did not alter the phenotypic traits of the cells and the rationale for using it was improvement of yield and adherence to culture vessels.

CATHEPSIN B CYTOCHEMISTRY AND STAINING OF LYSOSOMES

Cathepsin B activity within chondrocytes was evaluated with $\mathrm{N}$-carbobenzoxy-L-alanylL-arginyl-L-arginine-4-methoxy- $\beta$-naphthylamide (Z-Ala-Arg-Arg-MNA) (Bachem Ltd, Bubendorf, Switzerland) as the substrate, and the reaction product was coupled to 5-nitrosalicylaldehyde $e^{111819}$ to reveal cathepsin B-containing organelles as bright yellow spots in the fluorescence microscope. Control reactions were performed by including either $5 \mu \mathrm{mol} / 1$ leupeptin (Bachem Ltd) or $2 \mu \mathrm{mol} / 1$ L-trans-epoxy-succinyl-leucylamido(4-guanidino)-butane (E-64) (Sigma, St Louis, MO, USA). Lysosomes were visualised by vital staining of unfixed cells with acridine orange and fluorescence microscope detection. ${ }^{20}$

\section{CATHEPSIN B HISTOCHEMISTRY}

Cartilage cylinders were sampled as previously described $^{6}$ and immediately frozen in TissueTek $^{\circledR}$ OCT compound (Miles, IN, USA). Only cartilage remote from the osteophytes was considered. (Osteophytes contained the greatest cathepsin B activity in an OA joint, but these results will not be discussed here.) The unfixed and undecalcified blocks of tissue were allowed to reach the cabinet temperature of $-25^{\circ} \mathrm{C}$ before being cryosectioned with a hardened metal knife. After the tissue block was trimmed to the desired level, a piece of transparent Scotch tape 850 (3M, St Paul, MN, USA) was fastened on to its surface using a flat, medium-hard brush. Sections $10 \mu \mathrm{m}$ thick were obtained by cutting underneath the tape so that the tissue remained attached to it..$^{21-23}$ Cathepsin B activity was visualised on the tape adherent sections with Z-Ala-Arg-Arg-MNA (Bachem Ltd) as substrate and Fast Blue BB (Serva, Heidelberg, Germany) as the post- 
coupling reagent. ${ }^{23}{ }^{24}$ Incubation with the substrate was in the presence of $10 \% \mathrm{w} / \mathrm{v}$ polyvinyl alcohol, which very efficiently prevented diffusion of the reaction product. ${ }^{23}{ }^{24}$ Control reactions were performed by including either 5 $\mu \mathrm{mol} / /$ leupeptin or $2 \mu \mathrm{mol} / / \mathrm{E}-64$. The stained tissue sections adherent to tape were mounted in glycerol and immediately photographed. The severity of the OA lesions in all samples examined was graded according to Mankin et $a l^{25}$ as detailed previously. ${ }^{6}$ Bright field and fluorescence microscopic examination, and photography of cells and tissues were performed with a Zeiss Axiophot microscope.

\section{Results}

The table summarises details of the patients from whom OA femoral heads considered in this study were obtained. Although the primary indication for surgery of patients 007 and 011 was hip necrosis, they were included because the cartilage undoubtedly showed OA degeneration. Both femoral heads of nine individuals with no history of joint disease were analysed as controls. With OA cartilage obtained at surgery, the availability of tissue varied greatly from one sample to another, many femoral heads having just a few remnants of cartilage. Consequently, a choice was made for each as to whether cell cultures, enzyme histochemistry, or zonal enzyme distribution ${ }^{6}$ could be investigated. While only a representative few of the 1500 photographs produced in this study can be shown, the general trends they demonstrate will be considered.

\section{CATHEPSIN B IMMUNOCYTOCHEMISTRY}

Chondrocytes from normal and OA cartilage were left in F-12 medium just for the time necessary to adhere to cover slips for immunolocalisation experiments. The incubation conditions were not sufficient for phenotypic modulation, so that cathepsin B found within the cells was likely to represent the original enzyme content. After immunostaining, cathepsin B containing chondrocytes were characterised by the presence of brown cytoplasmic granules that remained unchanged for at least one year. A diffuse, non-specific and agranular brown colour was sometimes present in the controls because of a high dosage of nonimmune sheep IgG; this faded within two to four weeks in permanent mounts. Figure 1 (a-d) shows chondrocytes from four normal femoral heads (the other controls investigated behaved in the same way). Some of the cells from control cartilage adhered and spread on coverslips more easily than other cells but, independently of the donor's age, these cells contained only a few (fig $1 \mathrm{c}+, \mathrm{d}+$ ) enzyme positive granules, or none at all. As they were prepared from a pool of all zones of cartilage, they were heterogeneous and the cathepsin B containing cells may represent the fibrocytic type chondrocytes from layers proximal to the cartilage surface. ${ }^{4}$

Chondrocytes from OA cartilage contained conspicuous amounts of cathepsin B in a large number of cytoplasmic granules soon after isolation (fig $1 \mathrm{e}-\mathrm{h}$ ). Besides having a much greater cathepsin B content, OA chondrocytes were larger than normal cells, with a polygonal or a fibroblast like shape. To facilitate this comparison, all the photographs in figures 1 and 2 were taken using the same objective and were reproduced at the same final magnification. The OA chondrocyte population was also heterogeneous and included cells from cartilage types IV and V, but the isolation method adopted (discarding of the first pronase/trypsin digest) minimised possible contamination by foreign cells such as fibroblasts. The table summarises the cathepsin B content of the cells from nine additional patients.

Pathological specimens obtained at total hip arthroplasty: details of origin, and analysis of cathepsin $B$ in cells and cartilage

\begin{tabular}{|c|c|c|}
\hline $\begin{array}{l}\text { Patient, sex, } \\
\text { age }(y r) \text {, diagnosist, site }\end{array}$ & y) & athepsin $B$ activity in cartilage (histochemistry) \\
\hline 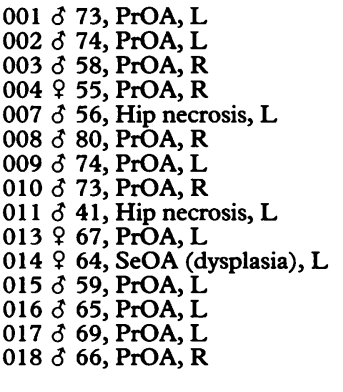 & $\begin{array}{l}90 \% \text { cells, +++, fig le } \\
90 \% \text { cells, +++, fig } 1 \mathrm{~g} \\
90 \% \text { cells, +++, fig } 1 \text { f }\end{array}$ & \multirow{2}{*}{ 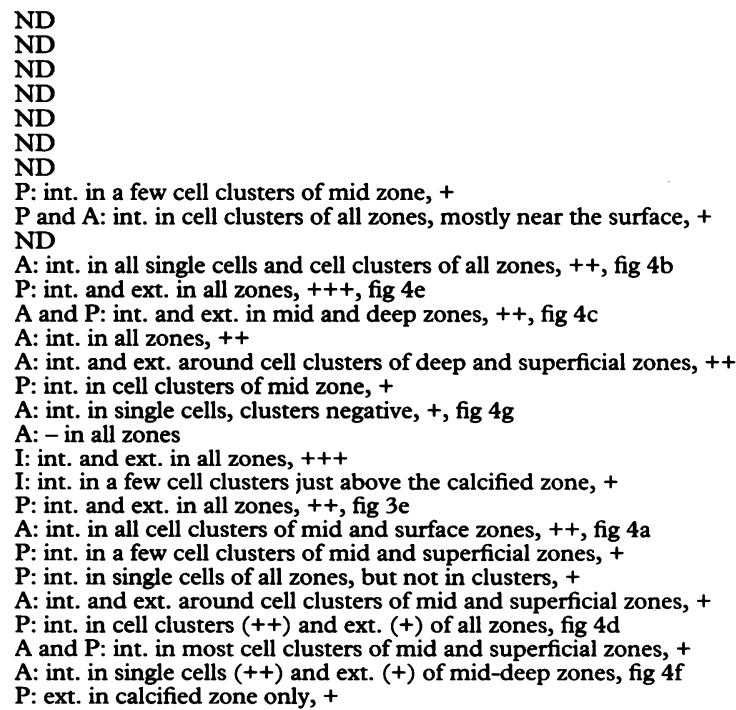 } \\
\hline 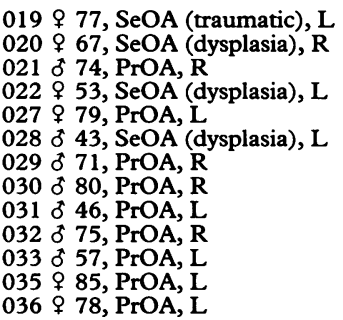 & $\begin{array}{l}\text { ND } \\
\text { ND } \\
\text { ND } \\
\sim 50 \% \text { cells, + } \\
\text { ND } \\
\text { ND } \\
\text { ND } \\
\text { ND } \\
>90 \% \text { cells, +++ } \\
\text { ND } \\
\text { ND } \\
\text { ND } \\
\sim 70 \% \text { cells, + }\end{array}$ & \\
\hline
\end{tabular}

†Diagnoses: $\operatorname{Pr}=$ primary idiopathic; Se=secondary; $O A=$ osteoarthritis. $L=$ left; $R=$ right. Qualitative intensity scale (histochemistry) and relative number of positive granules (immunocytochemistry): $-=$ none; $+=$ moderate/few; $++=$ strong/large; $+++=$ very strong/very large. $A=$ anterior; $P=$ posterior; $I=$ inferior. int. = intracellular; ext. = extracellular. $N D=$ not determined. 


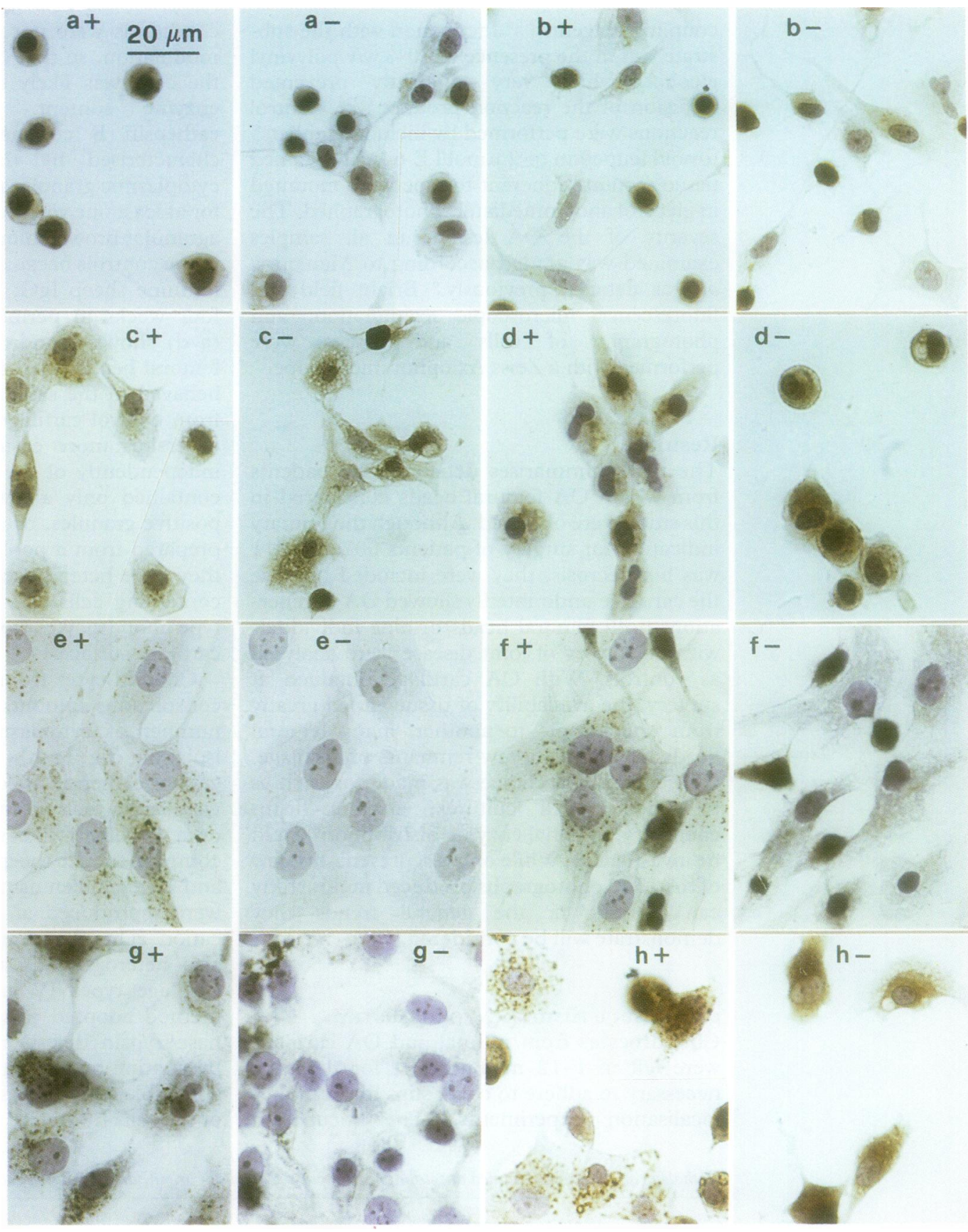

Figure 1 Immunolocalisation of cathepsin B in human femoral head chondrocytes. a: Control-2, 0 37 yr; b: control-4, o $25 \mathrm{yr}$; c: control-5, $930 \mathrm{yr}$; d: control-8, $978 \mathrm{yr}$; e: patient 001; f: patient 003; g: patient 002; h: patient 013 (patients' data summarised in the table). + = Staining with sheep antibodies against cathepsin B; $-=$ control with non-immune sheep IgG. The $20 \mu \mathrm{m}$ bar shown in panel $\mathbf{a}+$ is valid for all other panels.

PHENOTYPIC MODULATION AND STAINING OF LYSOSOMES

The cells of specimen control-5 shown in figure $1 \mathrm{c}$ were stained with acridine orange without prior fixation, a technique that is specific for revealing lysosomes in living cells, the lysosomes being coloured bright orange to red and the nuclei pale green. Forty hours after seeding, a large proportion of the cells did not contain appreciable amounts of lysosomes, some cells contained a discrete number of small, acridine orange positive granules, and only a very few contained lysosomes in sizeable amounts (fig 2a). The same chondrocytes (control-5) were subcultured in DMEM in the presence of $10 \%$ FCS. Figure $2 b$ shows that these cells were considerably enlarged and contained dramatically more cathepsin B positive granules after the third subculture, as detected by immunocytochemistry. The cells of other controls behaved identically (not shown). Also, the number of lysosomes stainable by acridine orange increased considerably after the third subculture in DMEM (fig 2c). Chondrocytes from OA cartilage (not modulated by subculture) contained a large number of lysosomes, comparable to that seen in artificially modulated cells (fig $2 \mathrm{~d}, \mathrm{e}$ ).

\section{CATHEPSIN B CYTOCHEMISTRY IN OA} CHONDROCYTES

From the results in the preceding sections (compare figure 1f,g and 2d,e) it is evident that the number of lysosomes in OA chondrocytes is much greater than the cathepsin $B$ positive 

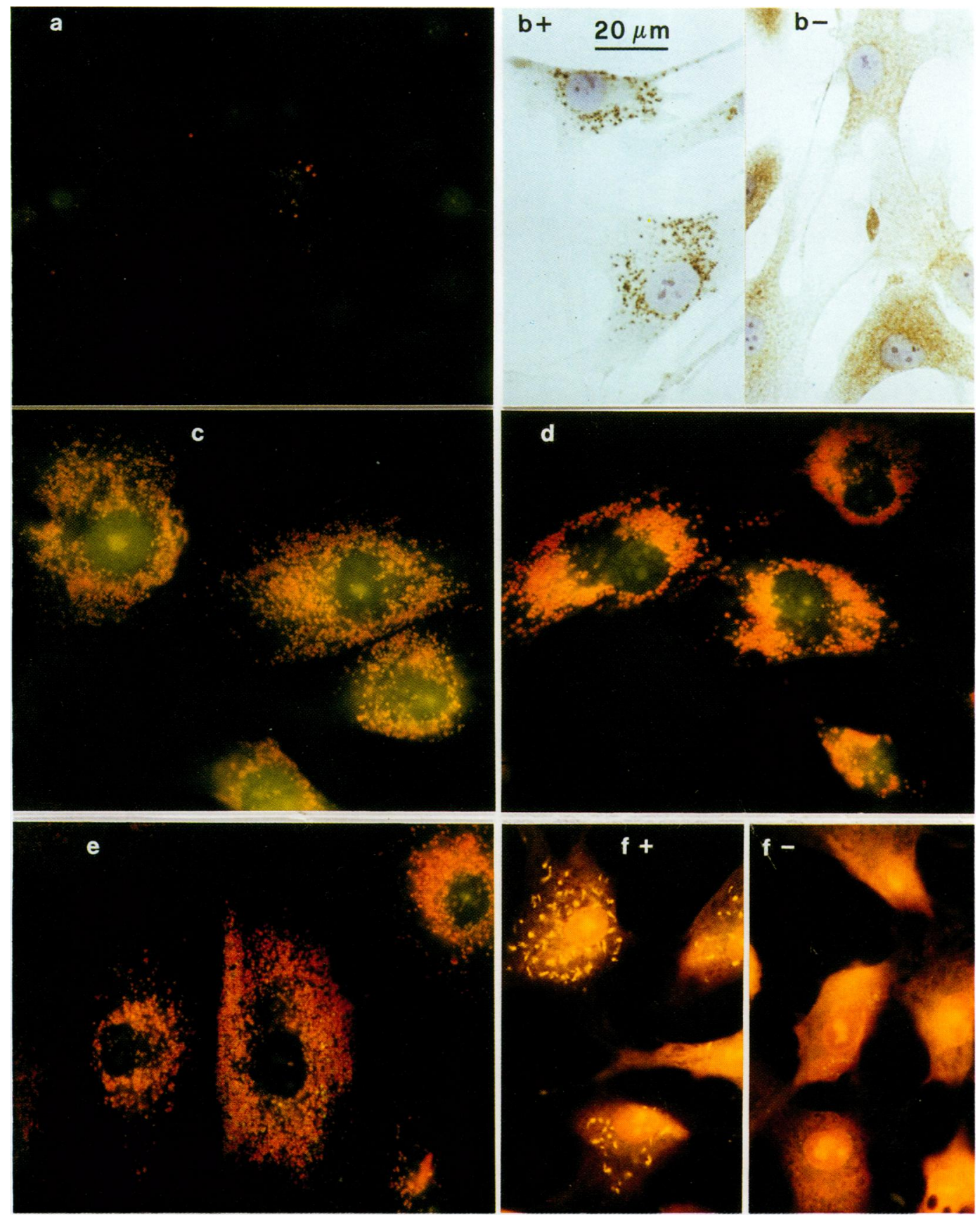

Figure 2 Staining of chondrocytes for lysosomes with acridine orange (bright orange to red fluorescence), and immunolocalisation (brown), and cytochemical (bright yellow fuorescence) demonstration of cathepsin B activity. a: Control-5, +30 yr; cells from the same experiment shown in figure 1c, 40 hours after seeding, stained with acridine orange. b: Immunolocalisation of cathepsin $B$ in the cells of control-5 after the third subculture $(+=$ staining with sheep antibodies against cathepsin $B ;-=$ control with non-immune sheep $\operatorname{IgG}$ ). c: Control-5 after the third subculture (cells from the same experiment shown in b) stained with acridine orange. d: Patient 003 (cells from the same experiment shown in figure 1f) stained with acridine orange. e: Patient 002 (cells from the same experiment shown in figure 1g) stained with acridine orange. f: Patient 002, cytochemical staining for cathepsin B activity ( $+=$ positive reaction; $-=$ control containing E-64 as inhibitor). Patients' data summarised in the table. The $20 \mu \mathrm{m}$ bar shown in panel $\mathbf{b}+$ is valid for all other panels.

granules as detected by immunocytochemistry. A further method was thus applied to stain cell organelles for cathepsin B activity (for example figure $2 \mathrm{f}$ ), and this confirmed that not all of the lysosomes made visible by acridine orange do contain cathepsin B.

\section{CATHEPSIN B HISTOCHEMISTRY}

Unfixed and undecalcified cryostat sections of normal and OA articular cartilage were stained for cathepsin B activity using a specific and sensitive method (figure 3 and 4; all photographs oriented with the cartilage surface up, cathepsin B containing areas showing as various shades of red). Two to four plugs of normal cartilage from each femoral head of nine individuals were carefully examined at high magnification in slices from various parts of the plugs. None of the specimens of control cartilage was stained positively for cathepsin B, as judged by comparing stained sections in the presence and absence of E-64. Three examples, from individuals aged 30,54 and 78 years are shown in figure $3 a-d$. To save space, the control reaction, performed in the presence of E-64 as cathepsin B inhibitor, is shown for just one sample (fig $3 \mathrm{~b}$ ). Cathepsin B activity 


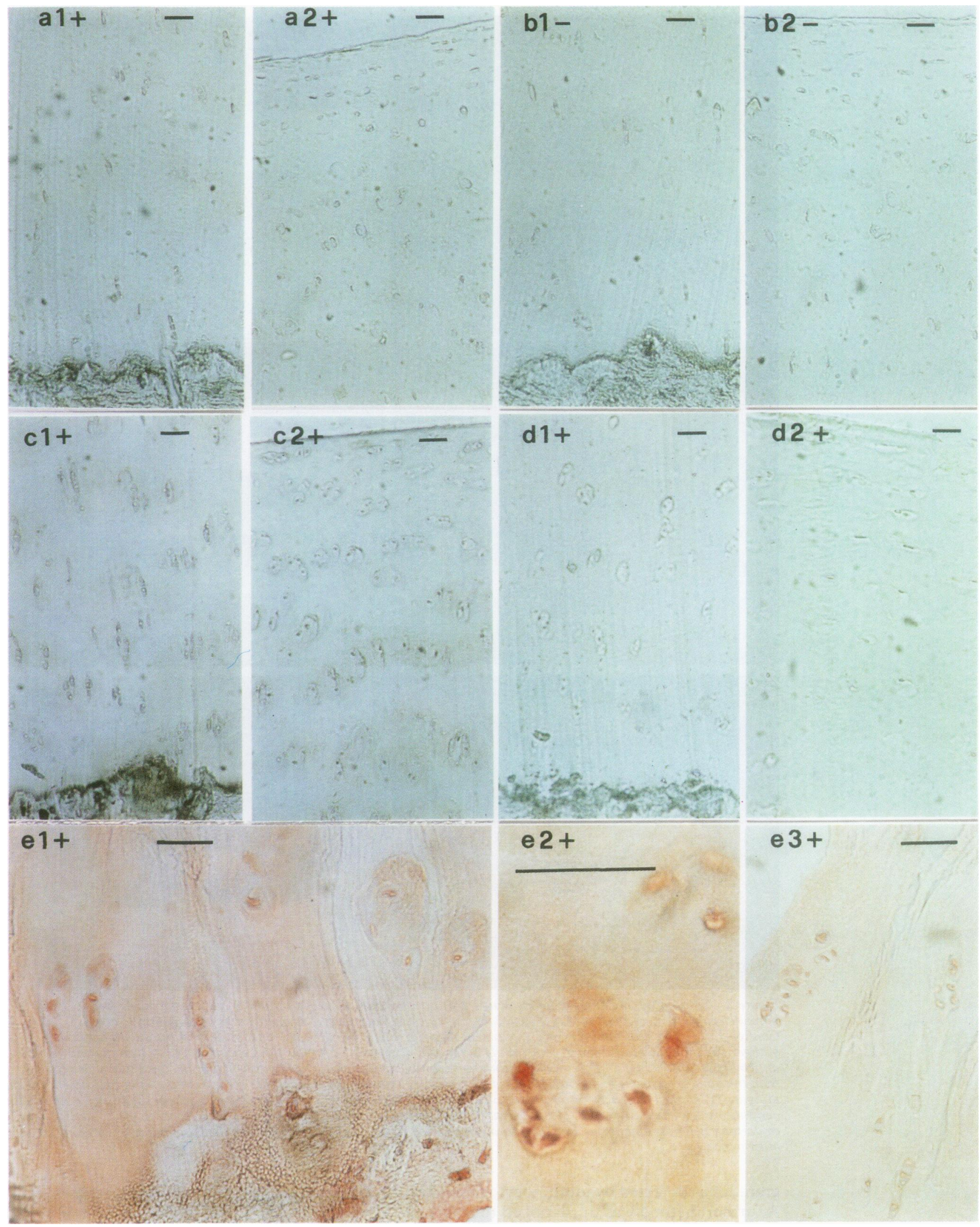

Figure 3 Histochemical demonstration of cathepsin B in unfixed, undecalcified cryostat sections of human femoral head cartilage. a, b: Control-9, $\delta 54$ yr (a1 and b1 lower zones, $\mathbf{a} 2$ and b2 upper zones of cartilage); $\mathbf{c 1}$ and $\mathbf{c 2}$ : control-5, +30 yr, lower and upper zones, respectively; d1 and d2: control8 , 978 yr, lower and upper zones, respectively; e: patient 027 (data in table) (e1 deep zones, $\mathbf{e} 2$ mid zone, e3 exposed, fibrillated surface). + = Positive staining; - = control in the presence of E-64. All bars represent $50 \mu \mathrm{m}$.

was not found in apparently intact or slightly damaged OA cartilage, while areas showing clear signs of destruction or remodelling stained positively (figs $3 \mathrm{e}, 4 \mathrm{a}-\mathrm{g}$ ). In all but one of the positive specimens (patient 036 in the table), enzyme activity was found within chondrocytes, while in just eight cases cathepsin B was also present in the matrix, and in patient 036 it was present only in the matrix (table). The assay solution included $10 \%$ polyvinyl alcohol to prevent enzyme diffusion and its omission caused colour diffusion as a gradient within a short range from the cells. ${ }^{24}$ Since activity in the matrix was not general to all 


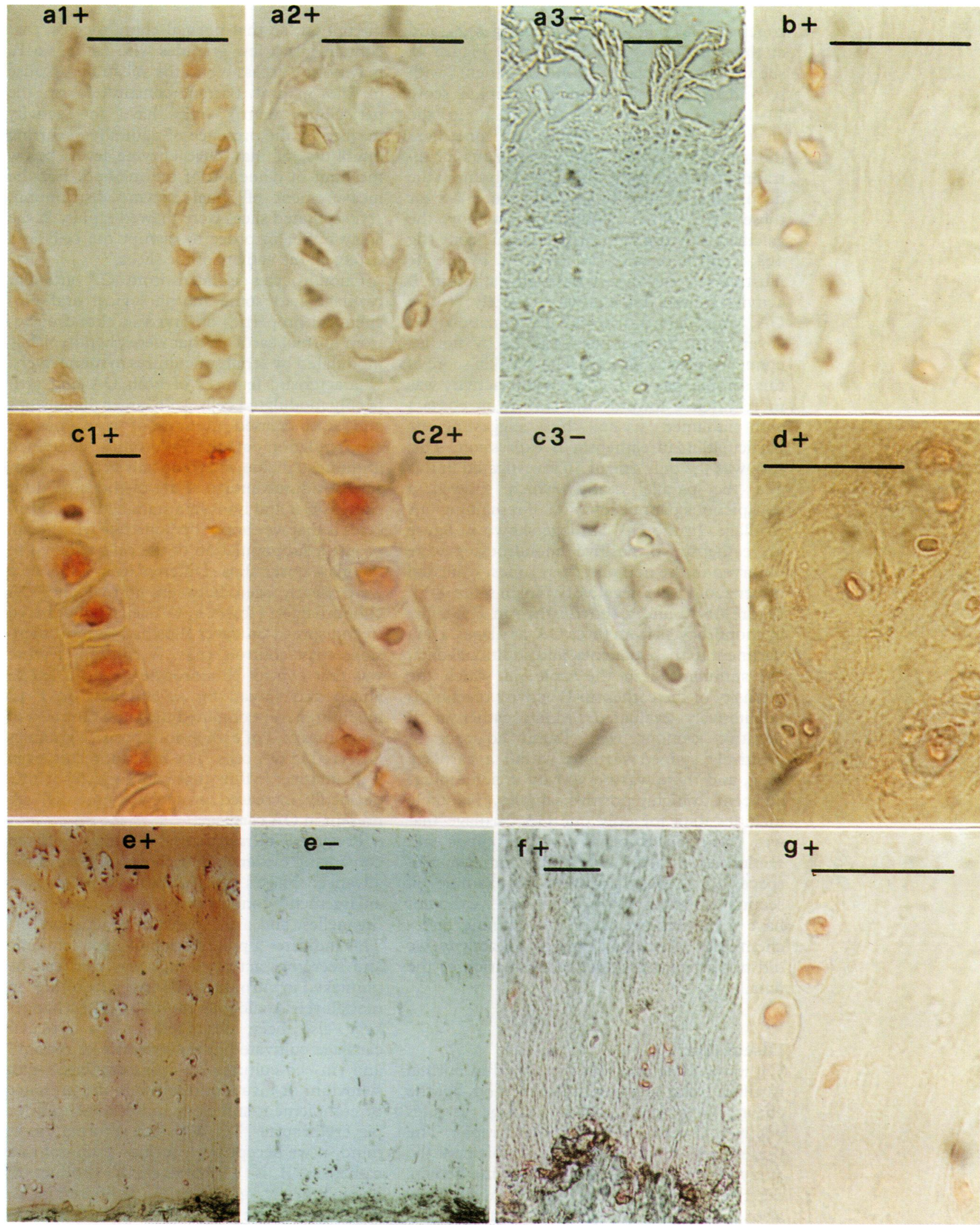

Figure 4 Histochemical demonstration of cathepsin B in unfixed, undecalcified cryostat sections of human femoral head cartilage. a: Patient 028, a1-a3 mid zone and near the exposed, fibrillated surface; b: patient 014, mid zone; c: patient 016, c1 chondrocytes from just above the calcified zone, c2 and c3 from the mid zone; d: patient 032, mid zone; e: patient 015, the remaining cartilaginous layer was covered by fibrous pannus (only cartilage shown); f: patient 035, mid-deep zones; g: patient 019, mid zone. Patients' data summarised in the table. $+=$ Positive staining; $-=$ control in the presence of E-64. All bars represent $50 \mu \mathrm{m}$ except in panels c1-c3 $(10 \mu \mathrm{m})$.

specimens and sections within the same specimen, and we adopted the necessary technical precautions, we describe this activity as being extracellular. In the cartilages of at least two patients (figs $3 \mathrm{e}, 4 \mathrm{e}$ ), extracellular activity was a regular feature in all sections of all plugs examined, and we trust that this finding is not an artefact of diffusion.

The cartilage sections in figure $3 \mathrm{e}$ were from a patient with primary OA (Mankin score 7-9 at that site) and show intracellular and extracellular cathepsin B activity in the deep 
zones (fig $3 \mathrm{e} 1$ ), in the mid zone (fig $3 \mathrm{e} 2$ ), and at the fibrillated surface (fig 3e3). Figure 4a shows the cartilage from a patient with secondary OA (hip dysplasia, Mankin score 11-12). Cathepsin B was present in the clustered chondrocytes in the mid zone, near the exposed surface and along clefts penetrating into the depth, while it was absent in the deep zones. Figure 4c (Mankin score 7-8 for these slices) shows cathepsin $B$ just above the calcified zone (fig 4c1) and in the mid zone (fig $4 c 2$; control reaction in fig 4c3). Figure $4 e$ illustrates a cartilage with high cathepsin B activity from a patient with severely erosive $\mathrm{OA}$, conspicuous synovial inflammation and covering of the residual cartilage by fibrous connective tissue pannus. The Mankin score of this sample was $8-9$, and enzyme activity was more intense towards the surface in contact with inflamed tissue, thus suggesting its participation in cathepsin B expression. This case was the only one of 36 investigated in this and the parallel study $^{6}$ which showed a conspicuous pannus invasion of remaining $O A$ cartilage. In the $\mathrm{OA}$ cartilage shown in figure $4 \mathrm{f}$, cathepsin B positive chondrocytes were observed in the mid and deep zones, while the upper zones were negative (Mankin score 4-5). Figure $4 \mathrm{~b}, \mathrm{~d}$ and $\mathrm{g}$ show cathepsin B activity in chondrocytes from three OA cartilages. Data pertinent to these patients, and additional data, are summarised in the table, in which the intensity of the cathepsin B activity reaction is qualitatively evaluated. Many cathepsin B negative sections were found adjacent to positively stained sections within a cartilage plug, and there was no activity in some plugs adjacent to highly positive samples. The table includes data for only one OA cartilage that was cathepsin B negative in all plugs and sections examined (patient 020 ), for reasons of space. As it was impossible to examine all sections obtainable from a plug and we did not have a quantitative mean for defining histochemically determined cathepsin B activity, we did not attempt a statistical evaluation of the data.

\section{Discussion}

Cathepsin B activity was not found in normal cartilage using a histochemical method, but the enzyme was seen in OA cartilage at sites involved in matrix destruction and repair. The present results agree with and complement the study of zonal distribution of enzyme activity determined by a quantitative method. ${ }^{6}$ They also extend valuable previous work on this subject ${ }^{1-5}$ by showing the location of enzyme activity in relation to anatomy and degree of joint cartilage destruction. Active cathepsin B was found within cells, particularly in clusters of proliferated cells, and more rarely in the extracellular space. There is an apparent discrepancy between the absence of histochemically determined cathepsin B in normal cartilage and the low, but still measurable, zonal activity measured with a fluorogenic substrate. ${ }^{6}$ For histochemistry, the cartilage slices were carefully protected to prevent cell disruption, so that normal chondrocytes, that contain just a few granules with cathepsin B, may not be accessible to the substrate because of the natural barrier constituted by the pericellular matrix, may have the activity masked by the presence of naturally occurring inhibitors, or may have enzyme levels below the limit of detection of the method. For the measurement of zonal enzyme distribution, cryosectioned slices were thawed rapidly in the assay buffer in order to disrupt the cells and detect all the activity of the slices. ${ }^{6}$

Chondrocytes isolated from $\mathrm{OA}$ articular cartilage had some morphological and biochemical properties observed in chondrocytes from normal cartilage that were phenotypically modulated by serial subcultures in monolayers. Characteristic features of both OA and artificially modulated cells were larger dimensions and an increased number of lysosomes. A subpopulation of the lysosomes contained immunostainable, enzymatically active cathep$\sin \mathrm{B}$. A disadvantage of the methods used for cathepsin B and lysosome staining in chondrocytes is that we cannot demonstrate whether all or just a subpopulation of the cells adhered to the glass cover slips. Differences in adherence were clearly seen between normal and OA chondrocytes. However, OA cells that adhered to and spread on cover slips had larger dimensions than controls cells. A constant feature was that control chondrocytes, even if left to attach and spread for several days in F-12 medium, never contained the large numbers of lysosomes and of cathepsin B positive granules observed in OA cells. The relevant result, even if qualitative, is thus that chondrocytes with a decidedly increased proteolytic potential are present in OA cartilage.

Previous ultrastructural studies offered convincing evidence that chondrocytes, in the advanced phases of $\mathrm{OA}$, undergo progressive enlargement, contain many more intracellular organelles, and are capable of replication. ${ }^{26} 27$ This indicates a potentiation of their synthetic and secretory activities in a way that can be mimicked in vitro through serial subcultures in monolayer. Analogous morphological changes have also been described in pig articular cartilage cultivated in the presence of retinol ${ }^{28}$ and in co-cultures of pig cartilage with synovium or invading marrow in the presence of complement-sufficient rabbit antiserum to pig erythrocytes. ${ }^{29}{ }^{30}$ With this information in mind, if we accept our previous proposal that cathepsin B is a characteristic product of phenotypically modulated (dedifferentiated) chondrocytes, we propose the working hypothesis that the enzyme observed in OA cartilage may be a product of chondrocytes that have undergone 'fibroblastic metaplasia'. This hypothesis does not preclude the (co)existence of other mechanisms. The high enzymatic content of these cells probably reflects a physiological demand for increased turnover of proteins in a tissue subjected to remodelling, but will any activity leaking into the matrix be sufficiently controlled?

The pooled results on histological, histochemical, immunocytochemical (this 
paper) and zonal activity analysis ${ }^{6}$ of OA cartilages in various stages of degeneration suggest that the mechanisms responsible for cartilage degradation at onset of OA may be different from those responsible for its perpetuation. We thus confirm our suggestion ${ }^{6}$ that cathepsin B may chiefly contribute to the chronicity of OA by perpetuating destruction despite evident efforts of repair.

We wish to dedicate this paper to the memory of Professor Albert Böni, pioneer of Swiss Rheumatology.

We are grateful to Professor A Schreiber and his staff at the Balgrist Orthopaedic University Clinic, Zurich, for supplying the surgical specimens, and to Professor J Schneider and Mr N Alder, Department of Pathology, University Hospital, Zurich, for their invaluable help in obtaining postmortem specimens. Supported by research grants from the Albert-Böni-Stiftung für Rheumaforschung, the Ciba-Geigy Jubiläumsstiftung and the Theodor und Ida Herzog-Egli-Stiftung.

1 Ali $S \mathrm{Y}$. The degradation of cartilage matrix by an intracellular protease. Biochem f 1964; 93: 611-8.

2 Ali S Y. The presence of cathepsin B in cartilage. Biochem 7 1967; 102: 10-11C.

3 Ali S Y, Evans L, Stainthorpe E, Lack C H. Characterization of cathepsins in cartilage. Biochem f 1967; 105: 549-57.

4 Bayliss M T, Ali S Y. Studies on cathepsin B in human articular cartilage. Biochem $\mathcal{F} 1978 ; 171: 149-54$.

5 Martel-Pelletier J, Cloutier J M, Pelletier J P. Cathepsin B and cysteine protease inhibitors in human osteoarthritis. f Orthop Res 1990; 8: 336-44.

6 Baici A, Hörler D, Lang A, Merlin C, Kissling R. Cathepsin B in osteoarthritis: zonal variation of enzyme activity in human femoral head cartilage. Ann Rheum Dis 1995; 54: 281-8.

7 Buttle D J, Saklatvala J, Tamai M, Barrett A J. Inhibition of interleukin 1-stimulated cartilage proteoglycan degradation by a lipophilic inactivator of cysteine endopeptidases. Biochem 7 1992; 281: 175-7.

8 Buttle D J, Saklatvala J. Lysosomal cysteine endopeptidases mediate interleukin 1-stimulated cartilage proteoglycan degradation. Biochem f 1992; 287: 657-61.

9 Buttle D J, Handley C J, Ilic M Z, Saklatvala J, Murata M, Barrett A J. Inhibition of cartilage proteoglycan release by a specific inactivator of cathepsin $B$ and an inhibitor of matrix metalloproteinases. Evidence for two convergin pathways of chondrocyte-mediated proteoglycan degradation. Arthritis Rheum 1993; 36: 1709-17.

10 Baici A, Lang A. Effect of interleukin-1 $\beta$ on the production of cathepsin $\mathrm{B}$ by rabbit articular chondrocytes. FEBS Lett 1990; 277: 93-6.

11 Baici A, Lang A, Hörler D, Knöpfel M. Cathepsin B as a marker of the dedifferentiated chondrocyte phenotype. Ann Rheum Dis 1988; 47: 684-91.

12 Baici A, Lang A. Cathepsin B secretion by rabbit articular chondrocytes: modulation by cycloheximide and glycosaminoglycans. Cell Tissue Res 1990; 259: 567-73.
13 Ali S Y, Bayliss M T. Enzymes involved in degradation of cartilage in osteoarthrosis. Ann Rheum Dis 1975; 34 (suppl 2): $65-6$.

14 Archer C W, McDowell J, Bayliss M T, Stephens M D, Bentley G. Phenotypic modulation in sub-populations of human articular chondrocytes in vitro. 7 Cell $S c i$ 1990; 97: 361-71.

15 Graf F M, Sträuli P. Use of the avidin-biotin-peroxidase complex (ABC) method for the localization of rabbit cathepsin $\mathrm{B}$ in cells and tissues. $\mathcal{F}$ Histochem Cytochem 1983; 31: 803-10.

16 Graf M, Baici A, Sträuli P. Histochemical localization of cathepsin $B$ at the invasion front of the rabbit V2 carcinoma. Lab Invest 1981; 45: 587-96.

17 Baici A, Gyger-Marazzi M. The slow, tight-binding inhibition of cathepsin B by leupeptin. A hysteretic effect. Eur f Biochem 1982; 129: 33-41.

18 Graf M, Leemann U, Ruch F, Sträuli P. The fluorescence and bright field microscopic demonstration of cathepsin B in human fibroblasts. Histochemistry 1979; 64: 319-22.

19 Dolbeare F, Vanderlaan M. A fluorescent assay of proteinases in cultured mammalian cells. $\mathcal{F}$ Histochem Cytochem 1979; 27: 1493-5.

20 Allison A C, Young M R. Vital staining and fluorescence microscopy of lysosomes. In: Dingle J T, Fell H B, eds. Lysosomes in biology and pathology, Vol 2. Amsterdam North-Holland, 1969 (reprint 1973); 600-28.

21 Rijntjes N V M, van de Putte L B A, van der Pol M, Guelen P J M. Cryosectioning of undecalcified tissues for immunofluorescence. F Immunol Meth 1979; 30: 263-8.

22 Van Noorden C J F, Vogels I M C. Enzyme histochemical reactions in unfixed and undecalcified cryostat sections of mouse knee joints with special reference to arthritic lesions. Histochemistry 1986; 86: 127-33.

23 Van Noorden C J F, Frederiks W M. Enzyme histochemistry: A laboratory manual of current methods. Oxford: Oxford University Press, 1992.

24 Van Noorden C J F, Vogels I L C, Smith R E. Localization and cytophotometric analysis of cathepsin $\mathrm{B}$ activity in unfixed and undecalcified cryostat sections of whole rat knee joints. F Histochem Cytochem 1989; 37: 617-24.

25 Mankin H J, Dorfman H, Lippiello L, Zarins A. Biochemical and metabolic abnormalities in articular cartilage from osteo-arthritic human hips. II. Correlation of morphology with biochemical and metabolic data. $f$ Bone foint Surg Am 1971; 53: 523-37.

26 Weiss C, Mirow S. An ultrastructural study of osteoarthritic changes in the articular cartilage of human knees. $\mathcal{f}$ Bone foint Surg Am 1972; 54: 954-72.

27 Weiss C. Ultrastructural characteristics of osteoarthritis. Fed Proc 1973; 32: 1459-66.

28 Barratt M E J. The role of soft connective tissue in the response of pig articular cartilage in organ culture to excess of retinol. $\mathcal{F}$ Cell Sci 1973; 13: 205-19.

29 Barratt M E J. Role of the chondrocytes in the breakdown of pig articular cartilage induced by complementsufficient antiserum to pig erythrocytes. Int Arch Allerg Appl Immunol 1975; 48: 547-63.

30 Fell H B, Barratt M E J, Welland $H$, Green R, Poole A R. The capacity of pig articular cartilage in organ culture to regenerate after breakdown induced by complementregenerate after breakdown induced by complement1976; 20: 3-21. 